\title{
DEFENSE RESOURCE MANAGEMENT SIMULATION IN BULGARIAN MINISTRY OF DEFENSE
}

\section{Bisserka BOUDINOVA}

simulation on defense resource management was held in the period 8-12
December 2003 at "G.S. Rakovsky" Defense and Staff College, Sofia, Bulgaria. The Bulgarian Ministry of Defense (MOD) organized the event in collaboration with the Institute for Defense Analyses (IDA).

The cooperation between the Bulgarian MOD and IDA dates back to the year 2000, when MOD launched a new defense resource management system based on a programming approach. Cooperation activities included one week working visits of American experts every month in 2000-2003. The same format is planned for 2004 to consider specific phases of resource planning and programming. The visits are focused on the development of the Integrated Defense Resource Management System (IDRMS), on the elaboration of its main documents, and on the harmonization of IDRMS with the principles of planning in NATO. Efforts have been directed to training of personnel, discussions with senior leaders on crucial issues in planning and programming, implementation of lessons learned, as well as on the ongoing Strategic Defense Review and especially on the creation of tools for precise costing of defense programs. As a result the Integrated Defense Resource Management System has improved considerably. At present, the system is in operation and four cycles of programming, leading to budget formulation, have been conducted. Future improvements are envisioned based on the accumulated practical experience.

\section{Purpose of Computer Simulation}

The importance and the results of the organized interactive computer simulation could be sought in the following directions: training of personnel and fostering of better understanding of the programming approach in defense resource management 
and promotion of the implementation of the Integrated Defense Resource Management System among the planning community in the Ministry of Defense.

The simulation was devoted to training of personnel involved at different management levels in the planning, programming and budgeting process. Representatives from the Defense and Staff College, the General Staff and the Ministry of Defense, the programming offices of the Services and representatives from the program teams of every major defense program participated in the simulation.

Computer simulation is of great importance for having well-educated experts in defense resource management. Some of the civil and military experts have only practical experience and need to learn more from theory; some are newcomers to the field and have to be trained in defense planning starting from the very beginning. The years of implementation of the new defense resource management system teach us that the education of personnel is a permanent activity. Furthermore, the education and training of senior leadership and other administrative staff, which influences decision-making, and units' staff, is a crucial factor for the proper functioning of the planning system and for gaining all the benefits from its implementation.

In addition, the simulation contributed to the strengthening of IDRMS as system for effective and efficient allocation of resources and for transparent decision-making in MOD and the Armed forces. It demonstrated the promise of IDRMS as a means for systematic, financially realistic, output-oriented planning and programming based on national defense policies. It further proved how essential it is to develop annual budgets and measure performance against the established objectives.

\section{Objectives of Computer Simulation}

The DRM Simulation is designed to improve host country defense resource management staff's understanding of a western-style defense resource management system that includes four interrelated phases: planning, programming, budgeting, and implementation of approved programs and budgets. At the same time it should explore interdependence of the processes, participants and products used in typical cycle of planning, programming, and budgeting of resources. The simulation uses a series of process-oriented, interactive workshops to familiarize participants with a broad range of the activities, roles and responsibilities, and analytical challenges encountered in such a management system. It is highly desirable that the attendees represent a cross-section of Ministry of Defense offices, General Staff, and Services staffs, and program manager offices. 
The interactive workshops emphasize important interrelationships and management concepts and are designed to give participants practical experience in:

- Developing and using key policy and analytic documents that are needed in a typical planning, programming, budgeting, and implementation cycle.

- Drafting selected work products (defense planning guidance, program proposals, program review issues, program decisions) that are generated within a defense resource management system and are consistent with senior leadership objectives within fiscal constraints.

- Assessing typical resource management issues and challenges encountered by senior civilian and military leaders and their supporting staffs during a cycle.

- Working collaboratively with representatives of multiple functional interests to develop solutions to resource allocation problems within a framework of national security policies.

- Presenting complex resource management issues for senior leader decision.

\section{Approach}

The simulation uses a dataset that describes a notional, medium-sized, military in a country with democratic rule and a market-based economy (Republic X). The workshops that comprise the core of the simulation involve a series of situations in this notional country. In addition to improving the people's standard of living, the new Government has decided to reduce and restructure the nation's Armed Forces to meet projected fiscal realities and a dramatically reduced military threat.

The workshops expose participants to a series of situations and tasks that typically take place in such an environment. They also enable participants to experience several different roles including the supporting staffs of the Minister of Defense, the Vice Minister of Defense for Resource Management, the Chief of Defense, key leaders of joint staff resource management offices, the commanders of major force elements, and major program managers. While simulating these roles, participants analyze complex situations, draft and debate key work products, and present the results of their work to senior decision makers who are played by the simulation facilitators. The facilitators form Resource board as an authorized decision-making body.

The simulation employs a simple force structure and macro-level planning factors that enable participants to explore the relative merits of alternative long-term resource allocation strategies and guidance. The data describe a military that needs to balance its readiness, force structure and modernization goals with the fiscal resources available. Simple force structure and associated cost factors are provided in an easy 
to use spreadsheet format that permits participants to calculate costs of current and potential alternative future forces and programs over a six-year program period.

The simulation has an introductory seminar and a workshop to explain the excelbased cost spreadsheet tool, eight process-oriented interactive workshops, and a concluding summary discussion period.

Workshop participants work in teams of approximately 8-9 persons and report the results of their efforts in a short briefing at the end of a workshop. Each workshop consists of a short introductory briefing, an interactive workshop and briefing to decision makers, and a short, structured concluding group discussion that focuses on important principles.

The objectives of the introductory seminar are to inform participants of the purpose and design of the simulation and to highlight the key features of the country scenario and the management system employed in the simulation.

The workshop's simulated activities include the following:

- Linking national policy and long-term planning to resource management in a fiscally constrained environment;

- Developing appropriate mid-term programming guidance and supporting administrative instructions;

- Translating guidance into realistic and affordable multi-year programs;

- Program review process;

- Developing program alternatives for consideration of executive management;

- Accommodating unanticipated changes in budget guidance;

- Resolving program-budget implementation issues at periodic reviews.

Let describe briefly the simulation activities and what is concrete objective of every activity. Exploring linkage between national policy and planning to resource management highlights the key features of the planning phase and the documents that are typically developed during this phase. It demonstrates the importance of developing realistic long-term plans and how long-term plans can provide key insights that influence development of the Minister's Defense Guidance.

Participants are given excerpts from several long-term plans (force structure, acquisition, facilities, and personnel management) to evaluate for consistency with the new government's defense reform objectives. They also are asked to determine how the plans should influence development of the upcoming Defense Guidance as well as to evaluate what aspects of the plans make them useful sources for developing an integrated resource strategy. 
Developing Ministerial Guidance highlights the primary purpose and key features of policy guidance from the Minister and the importance of establishing an underlying resource allocation strategy that influences development of the Guidance. This activity will stress on the importance of establishing realistic and quantitative Guidance objectives that can be linked to national objectives and used to measure progress of defense programs.

Participants evaluate several proposed additions to the latest draft Guidance in terms of their consistency with the Government's defense objectives and fiscal limitations. They also evaluate the level of detail that should be included in the Defense Guidance and the situation that is simulated in the workshop.

Program Preparation Instructions highlight the primary purpose of instructions for program managers and the considerations that should influence the scope and level of detail the document contains. The Program Preparation Instructions should comprise the format of program objective memorandum and the "display" of program that will be presented and submitted to senior managers at different levels of programming structure. Participation in this activity provides practical experience in estimation of appropriate level of detail for this document and what are the major factors that typically affect the requested scope of information presented.

Participants evaluate the level of detail that should be submitted by program managers, given the Minister's Guidance and the situation that is simulated in the workshop.

Program development demonstrates that clear consistent priorities and fiscally realistic programming guidance are essential for developing fiscally constrained program proposals. It proves the crucial importance and value of having in place a cost-analytic capability during the program development process. Participation in this activity provides practical experience that enables participants to translate Guidance objectives and priorities into an integrated multiyear program that addresses force structure, readiness and operations, sustainability, and investments. Program development reinforces the importance of having reliable cost information during the planning and programming phases and trained staff to make cost analyses.

Participants develop recommended programs for the Land Forces, Naval Forces and Air Forces using materials from previous workshops and the cost factor spreadsheet tool supplied. In addition to presenting the rationale for their recommended program, participants are asked to assess compliance with the Guidance, to indicate where fiscal constraints will necessitate missing or postponing Guidance objectives, and to develop a list of prioritized, unfunded requirements (modernization projects or investment projects). 
Program review process means to assess proposed programs that should be aligned with Programming Guidance of Minister of Defense. It highlights important factors supporting staffs should consider in assessing program manager developed multiyear program proposals. Participation in this activity provides practical experience in analyzing program managers' program recommendations, particularly in terms of their compliance with guidance, fiscal feasibility, internal consistency, and consistency with other programs. It is necessary to compare major program proposals and ensure cross-program linkages have been appropriately addressed.

Using the proposed programs developed in the previous event, plus summaries of the recommended programs of other defense activities, participants are asked to identify areas where the proposed programs fail to meet Guidance objectives at every level of hierarchical programming structure. The participants should analyze areas in which the programs may not be balanced when compare subordinated programs within major program or find that cross-program linkages may be inconsistent. They also are asked to identify and estimate alternatives using the cost spreadsheet and to prepare a presentation of potential program issues accompanied by analysis and alternatives for senior decision-maker consideration.

Developing and presenting program alternatives describe the role and typical concerns of senior decision-makers during the program review process as well as some important factors should be considered. Participation in this activity provides practical experience in developing appropriate program alternatives (to include funding increases and offsetting funding decreases) for senior leader consideration. The rule to follow in developing program alternatives is to build alternatives on the different ways of achieving program objectives, using various combinations of material, human, financial and time resources, but within given financial quotas for every program.

Participants develop and present briefings on major issues selected by senior leaders. Briefings presented describe the importance of the issue, address the major pros and cons of available alternatives, and identify the staff's preferred alternative and rationale for selecting the alternative.

Budget development and review process allow discussing the primary purpose and objectives of the budget development process and how it should relate to programming decisions. This activity highlights some important factors that should be considered in developing appropriate budget preparation guidance and assessing proposed budgets. Participation in this activity provides practical experience in linking programming and budgeting phases and accommodating unanticipated changes in budget guidance using focus on program goals and priorities. In budgeting phase the participants should understand the leading role of programs approved at the 
end of Program review process (in the final programming decisions made) and that budgets always serve to programs.

Participants are given a proposed budget revision that has been developed to comply with a last minute reduction in defense funding guidance for the coming budget year. Participants assess the proposal and develop an appropriate counter proposal.

Program-budget implementation and report identify the primary purpose and objectives of the implementation and status-reporting phase of activity and how it should influence the planning, programming and budgeting phases. This activity highlights some important factors that should be considered in developing appropriate program-budget implementation plans and status-reporting system. It points out that for having real and productive planning process there should be in place system for assessing periodic performance and issuing reports (for example, every three months and after the end of the fiscal year). These reports could help to meet program-budget implementation challenges and shortcomings and undertake corrective actions to ensure achievement of established priorities and objectives.

Participants are given a program-budget implementation report that contains several problems, e.g., program cost growth, acquisition slips that free near-term funds, training shortfalls, draw down delays and some unexpected cost growth. Participants must identify these problems, assess their severity and causes, and develop recommendations for senior leader decision.

\section{Implications}

While exercising how to develop the planning, programming, budgeting and execution processes in Republic X, the participants could draw a parallel line between this imaginary country and certain host country. Hence, the key factors for success in Republic X could be considered and applied for improving of defense resource management in host country.

Examining these factors in detail, we may observe situations and shortcomings that have been experienced and tackled by the Bulgarian MOD in recent years. We may further identify potential improvements in terms of requirements, responsibilities and commitments of different organizations in order to exploit the benefits of advanced defense resource management.

Key factors for success in planning phase are addressed in two directions:

- At the level of the Government: Clear statements of Government policy in basic documents (National Security Strategy, National Military Strategy), strategies that account for limited resources, a stable, multi-annual financial forecast from the Government, and clear statements of priorities. 
- Within the Ministry of Defense: Clear assignment of responsibilities for planning and a collaborative, transparent process, integrated long-range planning that accounts for financial limits, and annually issued Defense Guidance with clear statements of objectives, priorities, and financial limits.

The key factors for success in programming phase are:

- Sustained engagement by senior leaders and their commitment to use the system.

- Clear division of responsibilities between program managers, General Staff, and Ministry of Defense offices.

- Technical staff capable of preparing and assessing options for meeting program objectives set out in Defense Guidance. Staff should be able to analyze best combinations of capability and costs, be able to plan the proper integration of force structure, readiness, and modernization to achieve a balance that complies with policy priorities and makes sense from a military perspective.

- Above all, success requires everyone (staff experts, senior leaders) to accept the discipline of living within financial limits, and not to propose or make ad hoc decisions.

The key factors for success in the budgeting phase are:

- Key here is an understanding that the budget is derived from the program.

- Planners must be able to cope with unanticipated last-minute changes during budget preparation and implementation.

- But, after the program is adopted, the budgeting phase should not be the source of new substantive decisions unless absolutely necessary.

- A key technical requirement is the ability to portray the cost of the approved program within the national budget structure. This is the starting point each year for translating the first year of the multi-annual program into a budget request.

The key factors for success in performance monitoring phase are:

- Program managers and budget holders must report periodically on progress and problems, especially if the programming structure differs from set of budget holders.

- A formal analysis of performance reports must be made collaboratively by General Staff and Ministry of Defense resource offices.

- Significant problems must be presented to the senior leadership council (Defense Resource Board). 
- Problems must stay on the agenda of senior leaders until corrected The key factors for overall success of the implementation of new resource management system:

- All aspects of resource management should be transparent and collaborative.

- Resource management offices must have specialist staffs of adequate size.

- Staff experts, and supervisors, need adequate training.

- Senior leaders must know and understand their roles in the system.

- It is critical to adhere to the overall annual calendar for resource management, in order not to eliminate time for program review, which is one of the most important steps.

- Defense resource management reform will not succeed until resource offices have a capability for cost analysis and proper normative base for costing (methodology for calculating defense expenditures and agreed set of cost factors).

\section{Conclusion}

IDA experts conducted similar simulations on Defense Resource Management in several countries. They organized first test of the simulation in Romania during the first week of July 2003 at the Regional Center for Defense Resource Management in Brašov. The test was successful, and Romania adapted the simulation for use both in the Ministry of Defense and separately within the Romanian Air Force. The same simulation was conducted in Croatia during the last week of September 2003, and in Albania during the last week of October 2003. The results from all simulations have been exceptionally productive and promoted good governance practices. The interest of planning and programming experts and their willingness to study were considerable. The simulation may be used by every host country as a tool for further education of staff and future resource managers. In Bulgaria, for example, it already provided the basis for developing a regular course in the Defense and Staff College for training students in planning, programming, and budgeting.

This paper begins by defining CGF systems and grouping CGF simulation applications into three broad types. Calls in the CGF research literature for automated learning by CGF systems are surveyed. Categories of learning-modified behavior for CGF systems are defined based on what behaviors have been learned. Arguments are given, organized by application and behavior category, explaining how learning could increase and/or reduce the utility of the CGF system for the application. Real and notional examples are provided. Finally, specific applications where learning by CGF systems might be useful are identified. 